\title{
ESTATUTO DA CRIANÇA E DO ADOLESCENTE: UM RETRATO 30 ANOS DEPOIS
}

\section{Maíra Bonafé Sei}

Universidade Estadual de Londrina

Maria Lúcia Mantovanelli Ortolan

Universidade Estadual de Londrina

Nathália Tavares Bellato Spagiari

Universidade Estadual de Londrina

\section{Patricia Silva Lúcio}

Universidade Estadual de Londrina

Crianças e adolescentes são protegidos por lei em nosso país por intermédio do Estatuto da Criança e do Adolescente (ECA), documento que proporciona garantia de inúmeros direitos e que completou 30 anos em julho de 2020. Devido a sua grande importância, a revista Estudos Interdisciplinares em Psicologia reconheceu a necessidade de ressaltar o aniversário da promulgação de tal estatuto. Organizamos, assim, uma edição suplementar de textos sobre a temática em comemoração à data, muito embora o trabalho tenha sido atravessado por acontecimentos como a pandemia da COVID-19 e a mudança na Comissão Editorial de nosso periódico.

A pandemia enfrentada pelo mundo atualmente tem exigido um olhar crítico e cauteloso quanto à saúde física e mental de crianças e adolescentes, na medida em que as estratégias de contenção de transmissão do vírus incluem distanciamento e isolamento social, consequenciando inúmeras mudanças e adaptações do sistema educacional infanto-juvenil. Entendemos que, como previsto no ECA, para além de nossas condições de profissionais da área da saúde e das ciências humanas como um todo, as quais nos exigem responsabilização ética, nosso dever como cidadãos é de proteção às crianças e adolescentes, sendo essa edição suplementar um dos meios para o exercício deste dever.

Nesta edição, podemos observar a importância do ECA principalmente na garantia de direitos e de proteção a crianças e adolescentes que são escutadas em nosso sistema judiciário, por meio do depoimento especial, e aquelas que 
estão inseridas nas medidas socioeducativas, nos programas de privação de liberdade e nos acolhimentos institucionais. Em meio a estes contextos, os artigos aqui incluídos ressaltam as responsabilidades e desafios do trabalho da psicologia, do serviço social e de toda a equipe multidisciplinar a qual o tema complexo exige, principalmente no que compete às violências sexuais.

Isto posto, gostaríamos de agradecer aos autores que tiveram o interesse e disposição em publicar conosco, dando-nos o privilégio de compartilhar com o meio acadêmico suas experiências práticas e de pesquisa sobre a temática da criança e do adolescente. O agradecimento também se estende ao árduo trabalho dos pareceristas que, comprometidos com a importância e com os avanços da ciência, se dispuseram a avaliar os trabalhos submetidos.

\section{GERÊNCIA DE EDITORAÇÃO}

Dra. Maíra Bonafé Sei, Universidade Estadual de Londrina, Brasil

\section{CONSELHO EDITORIAL}

Dra. Acácia Aparecida Angeli dos Santos, Universidade São Francisco, Brasil Dra. Alexandra Anache, Universidade Federal de Mato Grosso do Sul, Brasil Dra. Andrea Bustos Ibarra, Pontificia Universidad Católica de Valparaíso, Chile Dra. Evely Boruchovitch, Universidade de Campinas, Brasil Dr. Manoel Antônio dos Santos, Universidade de São Paulo (Ribeirão Preto), Brasil Dr. Roberto Calazans, Universidade Federal de São João Del Rey, Brasil Dr. Sebastián Urquijo, Universidad Nacional de Mar Del Prata, Argentina

\section{COMISSÃO EDITORIAL}

Maria Lúcia Mantovanelli Ortolan, Universidade Estadual de Londrina Nathália Tavares Bellato Spagiari, Universidade Estadual de Londrina

\section{APOIO TÉCNICO}

Ana Carolina Moraes Silva, Universidade Estadual de Londrina 